James Madison University JMU Scholarly Commons

Department of Political Science - Faculty

Scholarship

Department of Political Science

2018

\title{
Educational development between faculty and administration
}

Andreas Broscheid

James Madison University, broschax@jmu.edu

Follow this and additional works at: http://commons.lib.jmu.edu/polisci

Part of the Secondary Education Commons

\section{Recommended Citation}

Broscheid, Andreas, "Educational development between faculty and administration" (2018). Department of Political Science - Faculty Scholarship. 1.

http://commons.lib.jmu.edu/polisci/1 
This essay employs Identity Theory to explore the professional identities of educational developers, arguing that it is important to pay attention to the different saliences, or weights, that developers attach to the faculty and administrative sides of their identities.

\section{Educational development between faculty and}

\section{administration $^{1}$}

Andreas Broscheid

After more than 15 years as a faculty member in political science, I recently made the switch to full-time educational development work. I had contributed to educational development programs before and found that they were among my most meaningful contributions to academia. Shortly after making the change, at a conference, I met several former fellow students and professors from grad school days. After I broke the news of my career change, my fellows had three questions: First, would I now have to wear a suit every day? Second, would I now have to go to work from 9 to 5 every day? Third, would I have to attend more meetings?

What I find interesting in this story is that my former fellow students and professors, all steeped in a world of disciplinary research and R1 institutions, without further questions, assumed that I was now an administrator, and that that role was defined by three properties: formal dress, formal hours, formal interactions. They did not have to ask what my appointment was, what my role at my institution was, what I did on a day-today basis. They simply knew. What I also find interesting is that my faculty colleagues at my

\footnotetext{
${ }^{1}$ Submission version of a paper to be included in a special issue of New Directions for
} Teaching and Learning on "Educational Development and Identity." March 2018. 
institution did not perceive me as an administrator. They knew me as a colleague, and it remained clear in conversations that the administration was still "them" and I was still I.

In this essay, I explore the puzzle raised by the confused faculty/administrative identities that we experience as educational developers. I explore the existing literature on developer identities and find that it reflects that confusion without providing a definite solution to the question of who we are. Then I take resort to sociology, specifically to Identity Theory (Stryker and Burke 2000), to get a clearer sense of what it means to have a (or several) professional identities. I argue that this exploration highlights some of the opportunities and challenges that we face as educational developers, and that it suggests the need for an explicit focus on professional identities in our collaboration with other developers and in the organization of development centers.

\section{What does the literature say?}

Over the last two decades or so, a wide-ranging and diverse literature has explored the professional identities of educational developers (see, for example, Andresen 1996; Jenkins 1999). This literature has not given rise to a cohesive picture: Educational developers are a diverse group of academics and professionals with a range of identities (see for example Dawson, Britnell, and Hitchcock 2010; Harland and Staniforth 2008). While few authors follow explicit definitions of identity, their arguments cluster into a series of contrasting and in part complementary conceptualizations: Most sources focus on the roles and activities of educational developers (Sugrue et al. 2017); others on the competencies that developers need to be effective (Dawson, Britnell, and Hitchcock 2010); others, on the types of appointments and positions of educational developers (Green and Little 2017); others on the self-identifications of educational developers (Green and Little 
2016); and a few on how others view educational developers (MacKenzie, McShane, and Wilcox 2007).

When it comes to the roles and activities of educational developers, a common theme is the diversity of what they do. Harland and Staniforth $(2008,669)$ characterize the field as "fragmented"; Dawson, Britnell, and Hitchcock (2010, 9-10), though focusing on competencies more than identities, illustrate this with a listing of the various activities of developers, such as facilitation, mediation, coaching, managing projects, and serving as specialists on higher education. Still, within this diversity of activities, there tends to be a common focus on supporting faculty in the triad of teaching, research, and service, with a particular focus on teaching (Taylor 2005).

A related commonality in the accounts of educational developers' activities is their role as educational experts and researchers on higher education. Sugrue et al. $(2017,1)$ note that educational developers are "helping colleges and universities function effectively as teaching and learning communities." Bath and Smith $(2004,23)$ argue that in the scholarship of teaching and learning, educational developers collaborate with disciplinary academics, while the study of higher education forms their specific area of enquiry. Taylor $(2005,41)$ characterizes the domain of educational development as "expertise about teaching, learning, and academic culture."

Methodologically, several authors argue that educational development is characterized by an approach that emphasizes facilitation and collegiality over direction, instruction, or training (Taylor 2005). Among the threshold concepts that Timmermans (2014, 311-313) identifies, "respecting and drawing out knowledge/expertise/ability" and "helping others realise their potential" are central, as is "collaboration and building 
relationships." The list of competencies identified by Dawson, Britnell, and Hitchcock (2010) confirms the collaborative focus of educational developers, with its emphasis on facilitating, mediating, and consulting.

Overall, several authors argue that educational developers, based on the activities that they engage in, are academics more than administrators (Bath and Smith 2004; Fraser and Ling 2014; Harland and Staniforth 2003; Green and Little 2016). A common view is that educational developers engage in the three areas of faculty activity: teaching, as they help faculty develop teaching skills (Fraser and Ling 2014; Green and Little 2016); scholarship, as they develop a "theory of higher education" (Harland and Staniforth 2003, 29); and service, through their leadership roles at their institutions (Taylor 2005). Still, the equation of educational developers with faculty may be a bit simplistic, as the findings on key competencies indicate that senior developers tend to be in more administrative roles than novice developers (Dawson, Britnell, and Hitchcock 2010).

The view of educational developers as (mostly) faculty gains further support from studies that focus on self-perceptions. This is most clear in the large survey of educational developers conducted by Green and Little (2016), who find that only about a third of their sample identify as purely administrative or managerial. The rest self-describe their work as faculty or mixed faculty/administrative. This is supported by other aspects of Green and Little's findings: Most educational developers have masters or doctoral degrees, teach, and do research.

There are some complications in the overall view of educational developers as faculty, though. Most importantly, their appointments are frequently in administrative or managerial. Green and Little (2017) show that less than half of the educational developers 
they surveyed held faculty positions. In the US, more than half in fact held administrative positions. This finding indicates that there is a conflict between educational developers' appointments and their predominant roles, activities, and self-perceptions.

Another counter-perspective that undermines the educational developers-as-faculty conclusion comes from studies that consider how others view developers. While there are few authors who investigate this aspect systematically, some of the voices in MacKenzie, McShane, and Wilcox (2007) report being othered by faculty they work with. Harland and Staniford (2003) note that their clients view them as administrators. A number of authors express this ambiguity of identities through the metaphors of migration and liminality (Little and Green 2012; Manathunga 2007). Instead of being faculty or administrators, educational developers are wanderers who cross boundaries and act from the margins. This enables them to bring in outside perspectives, to challenge, and to advocate for marginalized actors in academia.

\section{What do we mean by "identity"?}

Much of the literature fails to explain what is meant by "identity". Harland and Staniforth (2003) is an interesting case in point, as an entire section of their article is titled "Professional Identity" but does not include an explanation of how the authors define the concept. Similarly, Bath and Smith (2004) include the term "identity" frequently and in a variety of configurations but never explain what they mean by it.

Part of the reason for this lack of explicit definitions may be the fact that there are so many competing definitions of "identity" in a wide range of literatures, connected with a range of theoretical approaches (see, for example, Howard 2000). Avoiding explicit definitions and going with whatever common-sense intuition readers have in mind may be 
a strategy to avoid distracting theoretical debates. But if "by better articulating the identity of the academic developer, it is possible to determine what kind of community we are able to create" (Chadha and Sato 2015), then we should define "identity" more clearly.

I propose to focus the discussion on Identity Theory (see in particular Stryker and Burke 2000), a sociological approach that I find accommodates the identity overlaps and layerings of educational developers while providing a framework that integrates many of existing studies of educational developers' identities. Stryker and Burke's definition of "identity" explicitly acknowledges the multiple roles and layers of identity that we find among educational developers, referring "to parts of a self composed of the meanings that persons attach to the multiple roles they typically play in highly differentiated contemporary societies" $(2000,284)$. Educational developers play roles associated with faculty, but also roles associated with administrators, and possibly roles associated primarily with educational developers, and this layering of roles helps us understand their identities.

People hold positions in a range of social networks: they may be, for example, parents of school children, spouses, university professors, board members of local organizations. Along with those positions come expectations about how they should behave, what actions they should take, what values should be reflected in those actions: these expectations are social roles. Identities are accordingly defined as "internalized role expectations" (Stryker and Burke 2000, 286). The use of the plural "identities" is meaningful in this context: As humans are members of multiple social networks, they develop multiple overlapping identities. Identity Theory argues that those identities that are more salient are more likely to influence people's behavior. The salience of a particular 
identity, in turn, is influenced by a person's commitment, that is, the "degree to which persons' relationships to others in their networks depend on possessing a particular identity and role" (Stryker and Burke 2000, 286).

The link between identity and behavior, according to Stryker and Burke, is based on the creation of shared meanings: Social networks define situations and associated role expectations; people then define situations they encounter through their salient identity (287). For example, college professors who discover a plagiarized assignment most likely interpret this as a threat to academic integrity and report the plagiarizing student to their institution's honors council. Not penalizing and reporting the students so would diminish the professors' academic reputation. However, the situation is likely to be different if professors discover similar cheating activity among their own children. Then, in their role as parents, they would not be expected to report the cheating to the honors council; instead, the situation would more likely be interpreted as a parental educational challenge. In sum, Identity Theory argues that identities arise from our participation in social networks, through the positions we hold and the roles we play in them. Identities create meanings that help us interpret situations and decide how we should act in them.

\section{How does Identity Theory contribute to our understanding of who we}

\section{are?}

Framing the discussion of professional identities around Identity Theory has two advantages. First, Identity Theory clarifies how the different aspects of identity highlighted in the literature are connected: The focus on roles and activities in much of the literature is important because roles are central to identities; external expectations and self- 
perceptions are relevant in shaping commitments to identities; formal positions help understand the social networks that shape the salience of identities; cultural accounts of identity help us understand meaning-making. The second advantage of Identity Theory is that it provides a framework for analyzing multiple professional identities. The fragmentation of educational development (Harland and Staniforth 2008) is not necessarily due to different educational developers having different identities, but due to the fact that they attach different levels of salience to their common identities. This can help educational developers understand their commonalities and as well as their differences.

My main focus here is not on the causes of different levels of salience attached by developers to faculty and administrative identities, but on the consequences of such differences among developers: What does it mean to have multiple faculty/administrative identities, with different developers attaching different levels of salience to them? What are the advantages, opportunities, and challenges of multiple professional identities for communities of developers?

At a superficial level, the multiple, layered identities of educational developers simply imply that developers are engaged a particular mix of activities that are associated with different positions in different networks of academic professionals. Multiple professional identities can be associated with different, and partly contradictory, career paths, different criteria for career advancement, and different cultural values.

Many educational developers start their career as disciplinary academics who make a lateral move to the educational development field (Green and Little 2016). As such, their careers are focused on forms of teaching, scholarship, and service similar to disciplinary 
faculty work (Reybold 2003). As faculty, their work is characterized by disciplinarity, as they are specialists in their "home" academic discipline as well as in educational development itself. Their careers are dependent on disciplinary standards that evaluate whether publications, grants, and other academic achievements warrant reputation and professional advancement; reputation is largely governed by members of the developer's/faculty member's discipline-their "home" discipline as well as educational development—who may be located at institutions other than that for which the developer works (Fuller et al. 2006). Culturally, educational developers who identify mainly as faculty should be expected to display elements of Bergquist and Pawlak's collegial culture (Bergquist and Pawlak 2008), valuing disciplinarily, specialized expertise, faculty selfgovernance, and academic de-centralization.

Educational developers who identify mainly as administrators can be expected to be more focused on the interests of the whole academic institution instead of a particular discipline, with a preference for institution-wide cooperation and acceptance of hierarchical direction as a way to achieve cooperation (Birnbaum 1988; Del Favero and Bray). Their activities are more focused on organizational outcomes, hence requiring more regular work hours and careful coordinated planning processes, as one of my opening anecdotes to this essay suggests. Bergquist and Pawlak's (2008) managerial culture, with its valuation of clearly defined goals, structured planning towards educational outcomes, fiscal responsibility and effective hierarchical supervision, forms almost the stereotypical image of what administrative academics prefer.

These two identities are not always contradictory: Educational developers may enjoy faculty independence and specialization in their scholarship, while at the same time 
participating in institutional planning processes focused on overarching goals of higher education. But there can be conflicts, for example as educational developers become part of processes to achieve important institutional goals—say, educational development programs to support systematic assessment of learning—-that (are perceived to) interfere with faculty autonomy and disciplinary expertise (Di Napoli and Clement 2014; Manathunga 2007). In such conflictual situations educational developers' multiple identities matter-in positive and negative ways.

On the positive side, developers with strong administrative and faculty identities may be able to establish communication across different academic identities. As faculty, their teaching and scholarly profile may give them the credibility to engage in academic debates, offering the faculty case for institutional processes that support learning and an effective academic environment. For example, educational developers may be able to show that assessment can be a useful tool to evaluate teaching without taking resort to student evaluations of instruction. As participants in administrative processes, educational developers may be able to insert faculty perspectives into processes that otherwise may become top-down and removed from the reality of classrooms and faculty work flows.

The risk associated with educational developers' ability to be credible participants in faculty and administrative worlds is that they may become simply agents of one side or the other. A common concern is that educational developers will simply help academic planners create neoliberal institutions that are effective in processing students and attaining measurable research output but otherwise do not foster learning, intellectual exploration, and true innovation. In Manathunga's words, educational developers become "university management's teaching and learning foot soldiers" $(2007,26)$. 
Conflicting professional identities may be personally risky for individual educational developers as well. Stryker and Burke (2000) note the psychological difficulties associated with competing and conflicting identities. Particularly if those competing identities are equally salient, persons may experience stress and negative emotion. In Stryker and Burke's words, the result is “to stall or prevent behavioral repair of a gap between standards and perceived self-meanings" (290). The incidence of impostor syndrome may be one of the symptoms of this gap (Hutchins and Rainbolt 2017).

\section{What are the consequences for educational development centers?}

I believe that the brief analysis of educational developer identities that I have offered here helps us understand some of the advantages and challenges of our work and implies some strategies that educational development centers should pursue. These considerations also raise the question of whether a third, separate professional identity would be desirable for our work.

First of all, the layered identities of educational developers have advantages, as they allow us to cross the lines between faculty and administration and to ensure cooperation at academic institutions. This observation suggests that educational development centers will benefit from a diverse set of developers who attach different levels of salience to their faculty and administrative identities.

Such a diverse community of developers may pose a number of challenges, though. For one, educational development centers will have to make sure that their staff understand each other's differing identities and identity saliences, including their different roles, goals, and values for decentralized collaboration versus centralized coordination. In addition, centers should be open about the academic and political conflicts that they 
navigate between goal-oriented work that makes teaching, learning, and scholarship more effective and work that focuses on empowering faculty in the open pursuit of knowledge, creativity, and open-ended experimentation. At an individual level, centers have to be prepared to support educational developers who encounter stress due to their own conflicting professional identities.

While it is advantageous for educational developers to work in a community of colleagues with diversely layered identities, I note with Manathunga (2007) that this poses its own danger: As educational developers are able to get buy-in from faculty and cooperation from administrators, they may become the tools of a one-sided neoliberal vision of higher education. Educational developers can counter this risk through careful, reflective, politically conscious work that pays attention to dissenting voices in the academy. Or they should develop a separate professional identity beyond faculty and administration that is more difficult to co-opt.

There are some starting points for such a separate identity in the literature. Descriptions of educational developers as disciplinary "migrants" who work "on the margins" in an "unhomely environment" (Green and Little 2013, Manathunga 2007) provide metaphors for an identity that combines organizational experience with critical academic inquiry in a genuinely "ed. dev." way. Culturally, Bergquist and Pawlak (2008) suggest the existence of a developmental culture in academia whose focus is on the "personal and professional growth of all members of the higher education community" (73). Organizationally, there are undoubtedly social bases for the formation of educational developer identities through national and international professional associations, conferences, and the like. 
The development of a separate educational developer identity may be on its way, whether we like it or not. From an Identity Theory perspective, though, our enthusiasm for such a development should be cautious: The combination of multiple professional identities, and the collaboration in teams of professionals with different identity saliences, has advantages that I am not sure we would want to lose. Furthermore, it is more likely that an educational developer identity would be layered on top of faculty and administrator identities, reinforcing conflicts and stressors that educational development centers will have to contend with. We may be well-served by our current state of two-layered hybrid identities.

\section{References}

Andresen, Lee. 1996. "The Work of Academic Development - Occupational Identity, Standards of Practice, and the Virtues of Association." International Journal for Academic Development 1 (1): 38-49.

Bath, Debra, and Calvin Smith. 2004. "Academic Developers: An Academic Tribe Claiming Their Territory in Higher Education." International Journal for Academic Development 9 (1): $9-27$.

Bergquist, William H., and Kenneth Pawlak. 2008. Engaging the Six Cultures of the Academy. San Francisco: Jossey-Bass.

Birnbaum, Robert. 1988. How Colleges Work: The Cybernetics of Academic Organization and Leadership. San Francisco, Calif.: Jossey-Bass. 
Chadha, Deesha, and Hiroaki Sato. 2015. “Knowing Me, Knowing You: UK and Japanese Academic Developer Identities at Two Research-Intensive Institutions." International Journal for Academic Development 20 (3): 266-78.

Dawson, Debra, Judy Britnell, and Alicia Hitchcock. 2010. "Developing Competency Models of Faculty Developers." To Improve the Academy 28 (1): 3-24.

Del Favero, Marietta, and Nathaniel Bray. 2005. "The Faculty-Administrator Relationship: Partners in Prospective Governance?" Scholar-Practitioner Quarterly 3 (1): 53-72.

Di Napoli, Roberto, and Mieke Clement. 2014. "The Agency Game in Academic Development: Compliance and Resistance." International Journal for Academic Development 19 (1): 1-3.

Fraser, Kym, and Peter Ling. 2014. "How Academic Is Academic Development?" International Journal for Academic Development 19 (3): 226-41.

Fuller, J. Bryan, Kim Hester, Tim Barnett, Len Frey, and Clint Relyea. 2006. “Perceived Organizational Support and Perceived External Prestige: Predicting Organizational Attachment for University Faculty, Staff, and Administrators." Journal of Social Psychology 146 (3): 327-47.

Green, David A., and Deandra Little. 2013. "Academic Development on the Margins." Studies in Higher Education 38 (4): 523-37.

———. 2016. "Family Portrait: A Profile of Educational Developers Around the World." International Journal for Academic Development 21 (2): 135-50.

———. 2017. "On the Other Side of the Wall: The Miscategorization of Educational Developers in the United States?" To Improve the Academy 36 (2): 77-88. 
Harland, Tony, and David Staniforth. 2003. "Academic Development as Academic Work." International Journal for Academic Development 8 (1-2): 25-35.

——-. 2008. "A Family of Strangers: The Fragmented Nature of Academic Development." Teaching in Higher Education 13 (6): 669-78.

Howard, Judith A. 2000. "Social Psychology of Identities." Annual Review of Sociology 26: 367-93.

Hutchins, Holly M., and Hilary Rainbolt. 2017. "What Triggers Imposter Phenomenon Among Academic Faculty?" Human Resource Development International 20 (3): 194-214. Jenkins, Alan. 1999. “Turning Academics into Teachers: A Response from a 'Non-academic' Unit." Teaching in Higher Education 4 (2): 281-84.

Kensington-Miller, Barbara, Joanna Renc-Roe, and Susan Morón-García. 2015. “The Chameleon on a Tartan Rug: Adaptations of Three Academic Developers' Professional Identities." International Journal for Academic Development 20 (3): 279-90.

Little, Deandra, and David A. Green. 2012. "Betwixt and Between: Academic Developers in the Margins." International Journal for Academic Development 17 (3): 203-15.

MacKenzie, Heather, Kim McShane, and Susan Wilcox. 2007. “Challenging Performative Fabrication: Seeking Authenticity in Academic Development Practice." International Journal for Academic Development 12 (1): 45-54.

Manathunga, Catherine. 2007. “Unhomely’ Academic Developer Identities: More Post-colonial Explorations." International Journal for Academic Development 12 (1): 25-34. Reybold, L. Earle. 2003. "Pathways to the Professorate: The Development of Faculty Identity in Education." Innovative Higher Education 27 (4): 235-52. 
Stryker, Sheldon, and Peter J. Burke. 2000. "The Past, Present, and Future of an Identity Theory." Social Psychology Quarterly 63 (4): 284-97.

Sugrue, Ciaran, Tomas Englund, Tone Dyrdal Solbrekke, and Trine Fossland. 2017. “Trends in the Practices of Academic Developers: Trajectories of Higher Education?" Studies in Higher Education.

Taylor, K. Lynn. 2005. “Academic Development as Institutional Leadership: An Interplay of Person, Role, Strategy, and Institution." International Journal for Academic Development 10 (1): 31-46.

Timmermans, Julie A. 2014. "Identifying Threshold Concepts in the Careers of Educational Developers." International Journal for Academic Development 19 (4): 305-17.

Andreas Broscheid is an assistant director at the Center for Faculty Innovation and a professor of political science at James Madison University. 